\title{
EDITORIAL
}

\section{TRANSFERTS CULTURELS}

Au milieu des années 1980, en France et dans l'espace franco-allemand s'est développée, la notion de transfert culturel qui insiste sur la complexité des processus de déplacement, notamment dans le champ des études littéraires et historiques. Cette notion exclut tout appauvrissement des contenus initiaux dans le passage d'un objet culturel d'un contexte à un autre et appelle à croiser les approches de type herméneutique et sociologique dans la circulation des œuvres, des théories, des livres. Le terme « transfert culturel » met au premier plan l'idée de circulation, de passage, un va-et-vient qui intègre de multiples phénomènes tels que l'intertextualité, la traduction, la réécriture, etc. sans privilégier le point de départ, en remettant en cause la catégorie de l'influence, qui suppose l'ascendant d'une culture sur une autre et une sorte de hiérarchie, mais en insistant sur la dynamique de resémantisation. L'étude des transferts culturels ne vise surtout pas à comparer les cultures mais à suivre le détail des imbrications et interactions qui les constituent. Comprendre un transfert culturel implique souvent que l'on prête attention à l'histoire des livres, des bibliothèques, de l'acquisition des savoirs, notamment linguistiques et de toutes les étapes d'une médiation.

Afin de contribuer à la cartographie des études en cours dans ce domaine de recherche, la revue Jangada a proposé un dossier dédié aux transferts culturels, visant à provoquer une discussion qui aborde le panorama des usages spécifiques du concept, les objets auxquels l'appliquer et la pratique de chaque recherche, compte tenu de la diversité et de la multiplicité des perspectives offertes par le thème. Ainsi, ce dossier vise à approfondir la réflexion sur les transferts culturels, que ce soit au niveau des rencontres littéraires et de la théorie littéraire, ou dans la recherche de nouveaux points de vue au sein de l'historiographie culturelle. Et, nous avons réalisé une ample moisson de contributions en incitant professeurs et chercheurs à présenter leurs travaux - ce que le lecteur pourra vérifier en scrutant les articles qui composent le dossier. 
Nous avons divisé celui-ci en cinq séquences. La première, consacrée aux relations Brésil-France sous leurs multiples aspects, valorisant la production romanesque, lyrique et journalistique à partir des auteurs abordés. Dans « Les échos des révolutions de 1848 au Brésil: formes de pensée, littérature politique et transferts culturels », premier article de ce dossier, Marisa Midori Deaecto analyse, à partir de la lecture des journaux de Rio, non seulement les débats politiques soulevés au Brésil durant la période des révolutions de 1848, mais aussi le comportement de la presse et les partis pris des faiseurs d'opinion par rapport aux événements révolutionnaires.

Alors que sera bientôt célébré le centenaire de la disparition de Marcel Proust, Fillipe Mauro offre avec «Ó mon petit Marcel : quatre poèmes brésiliens sur Proust », un article dans lequel l'auteur part d'un poème de Paul Morand consacré à Proust, pour envisager la production d'Augusto Meyer, João Cabral de Melo Neto, Jorge de Lima et Cláudio Murilo Leal, des poètes qui, chacun à leur manière, « lisent » la Recherche selon une esthétique intertextuelle, l'intégrant à leurs productions lyriques et artistiques. «L'« école réaliste » française : une invention du théâtre brésilien ? (années 1850-1860)", de Daniel Polleti, se tourne vers le théâtre de boulevard, genre « adopté par les hommes de lettres brésiliens »dans les années 1850 et 1860. L'auteur explique comment la dramaturgie réaliste a prospéré au Brésil et a provoqué des transformations dans les arts et la société , donnant un nouveau sens aux processus intellectuels de la tradition locale. Dans «Le Brésil télégraphié : l'impact des nouvelles technologies de l'information sur la circulation d'objets et de médiateurs culturels entre le Brésil et la France (1874-1899) », Tanize Costa Monnerat traite des publications françaises de la fin du XIXe siècle et de l'avènement de nouvelles technologies (télégraphe et agences de presse), qui ont provoqué la « révision des anciennes pratiques journalistiques et l'exploration de nouveaux thèmes », permettant l'émergence d'une nouvelle image du Brésil. Grace Alves da Paixão, à son tour, dans «Sérgio Buarque de Holanda : rencontres littéraires France-Brésil (1920-1930) », se concentre sur l'œuvre de Buarque de Holanda en tant que critique lié aux avant-gardes modernistes, révélant le regard d'un intellectuel inquiet qui, entre autres aspects, dévoile une profonde interconnexion avec la France, un pays avec lequel il avait de nombreuses affinités. Et, pour achever cette séquence consacrée aux relations Brésil-France, Yue QI, avec « Mettre la 'Chine contemporaine' à l'épreuve des transferts culturels franco-brésiliens : le cas de Mon Pays », dans une parfaite triangulation des transferts culturels, retrace la création, la publication, la traduction et la diffusion de l'ouvrage Mon Pays, où le diplomate chinois Chen Jitong analyse 
les images littéraires de son pays dans des contextes franco-brésiliens afin de comprendre un chevauchement culturel sino-franco-brésilien.

Dans la séquence suivante, nous avons deux articles qui traitent de la réception : Ye XU, dans «La poésie de Verlaine et la poésie chinoise dans la perspective de la réception », réfléchit aux rapprochements de la poésie chinoise, dans les années 1910 à 1930, avec la poésie de Paul Verlaine, figure emblématique du poète maudit. Les poèmes de Verlaine ont trouvé des échos dans l'évolution de la poésie chinoise, qui cherchait sa modernisation et restait en même temps sensible à l'héritage de la tradition. Verlaine ainsi était perçu comme un révolutionnaire pour sa liberté de versification, les Chinois cherchant à dépasser la prosodie ancienne et canonique. Earl Fitz, également concerné par la question de la réception dans « La réception de la littérature brésilienne aux États-Unis », réfléchit sur sa propre expérience au cours des années d'enseignement durant lesquelles il s'est consacré à la recherche de « la littérature interaméricaine aux États-Unis », nous offrant un aperçu de la lecture des œuvres brésiliennes par les Américains.

Dans la troisième séquence, la question coloniale et post-coloniale, bien que sous des angles différents, est présente dans trois articles du dossier. Michel Espagne, dans «Alexander von Humboldt et la construction franco-allemande de l'Amérique Latine », se tourne vers l'écrivain, naturaliste et explorateur francophone allemand, engagé dans la préparation des plus de 30 volumes en français qui composent le Voyage aux régions équinoxiales du nouveau continent, et, selon l'auteur, représentent un transfert culturel triangulaire paradigmatique. Van Quang Pham, dans « La reconfiguration des pensées occidentales au Sud-Vietnam postcolonial », montre comment des intellectuels vietnamiens, en pleine crise morale et matérielle, se sont réfugiés dans des réflexions philosophiques, recourant aux idées occidentales comme manière d'agir et de vivre dans leur pays. Hans-Jürgen Lüsenbrink, quant à lui, fait marche arrière dans le temps et nous ramène au temps des conquérants espagnols dans « Communication interculturelle et transferts culturels dans le contexte colonial. La rencontre entre Pizarro et Atahualpa en 1532 et ses représentations discursives dans les cultures de l'époque moderne », un article qui aborde la question des représentations historiques de la rencontre entre le roi des Incas, Atahualpa, et le conquérant Francisco Pizarro, au XVIe siècle, à travers différents discours produits par les Espagnols qui ont contribué à la construction d'une version officielle du célèbre épisode, aujourd'hui revisité par d'innombrables historiens.

Dans l'avant-dernière séquence du dossier, nous présentons des articles dont les contributions, dès le titre, expriment le thème du transfert culturel. Ekaterina Dmitrieva, dans Jangada | ano 9, nr. 17, jan/jun, 2021 | ISSN 2317-4722 
«Les prémisses du transfert culturel dans les sciences humaines russes du XIXe siècle : la contribution de Vladimir Stasov », met en lumière le Russe Vladimir Stasov, promoteur d'un tout premier et très spécifique comparatisme russe, éminent critique d'art et auteur « d'un certain nombre d'études, dans lesquelles, tout en défendant l'idée d'art national, il [a tenté] en même temps de prouver la continuité de l'art russe par rapport à l'art asiatique », ce qui conduit à s'interroger sur l'« exigence identitaire » dans la littérature russe. La contribution de Rubens Vinícius Marinho Pedrosa et Pedro Paulo Garcia Ferreira Catharina, « Naturalisme et transferts culturels : le cas France-Belgique », traite des échanges artistiques-intellectuels entre les écrivains Camille Lemonnier et Joris-Karl-Huysmans, soulignant la façon dont la communication entre les deux favorise la circulation des idées et contribue à un transfert culturel non seulement entre les éditeurs, mais aussi entre les littératures des deux pays, puisque Lemonnier était Belge et Huysmans Français. Dans les trois articles suivants, Anne-Frédérique Schläpfer, dans «Le genre national comme transfert culturel», propose pour commencer, à partir de la notion de transfert culturel, d'envisager les relations entre littérature francophone et non francophone, et, pour cela, aborde le phénomène littéraire dans la perspective de genres nationaux, réfléchissant à la manière dont le roman anglais a façonné la francophonie entre les années 1920 et la fin des années 1940. Romuald Valentin Nkouda Sopgui, à son tour, dans « (Auto)biographies - parallèles et médiation culturelle transnationale : une lecture de la littérature germano-africaine à partir de la notion de «transfert culturel » », analyse, à partir de leurs parcours biographiques, la circulation des auteurs africains en Allemagne, mettant l'accent sur « les différentes médiations transnationales et transculturelles ». Enfin, dans «Presse périodique franco-américaine : connexions, transferts et identité », Valéria dos Santos Guimarães nous propose « une vue d'ensemble sur la publication des périodiques francophones édités en Amérique du Nord, Centrale et du Sud aux XIXe et XXe siècles », dans la perspective des transferts culturels entre la France et les différents pays du continent américain.

La dernière séquence du dossier se termine par deux articles qui présentent des perspectives sur la culture occidentale en relation avec d'autres cultures. Miki Okubo, dans « La notion de «gothique » traduite dans la culture pop du Japon contemporain », traite du mouvement « gothique et Lolita » au Japon, résultat non seulement de l'admiration japonaise pour la culture occidentale et le monde enfantin en tant que trait culturel, mais aussi pour ses imbrications littéraires, puisque le concept a été emprunté au roman de l'écrivain russe, naturalisé américain, Nabokov. Et enfin, Mahamadou Lamine Quedraogo, dans « Repenser l'épistémologie des sciences en Afrique : les cultures africaines comme stratégie de mieuxJangada | ano 9, nr. 17, jan/jun, 2021 | ISSN 2317-4722 
être », esquisse le statut secondaire de la culture au Burkina Faso et aborde les aspects épistémologiques du développement et le fait que la communauté internationale comprend l'Afrique à partir d'un référentiel de modèles de connaissance entièrement occidentaux. L'auteur suggère la déconstruction de ces modèles et propose de « repenser l'épistémologie des sciences de la nature à la lumière des cultures africaines afin de faire de la science en Afrique le témoin de la pensée africaine ».

Dans la section Varia, nous incluons la contribution de Redha Benmessaoud qui dans «Glottopolitique(s) et pouvoir(s) : textes et contextes » revisite le concept de glottopolitique, forgé par Louis Guespin, à partir de périodes spécifiques de l'histoire européenne, délimitant la manière dont les langues ont été « soumises » par les politiques des puissances totalitaires du moment, représentées ici par Mustafa Kemal Atartürk, Staline, Hitler et Mussolini. Ensuite, Erick Araujo dans «Lima Barreto : littérature, musique et existences », nous apporte « une relecture des propos de Lima Barreto sur la musique populaire » en proposant « une analyse des critiques adressées à l'auteur ».

Pour conclure ce numéro consacré aux transferts culturels, nous apportons le texte de François Weigel, commentant l'ouvrage récemment publié d'Étienne Sauthier, Proust sous les tropiques. Diffusion, réceptions, occasions et traduction de Marcel Proust au Brésil (19131960), ouvrage qui interroge les multiples facettes de la réception de Proust au Brésil, notamment chez les intellectuels brésiliens, montrant qu'il apparaît comme un exemple non seulement de la circulation des idées, mais de transfert culturel en tant que phénomène capable d'« embrasser » les déplacements culturels dans leur intégralité.

Pour conclure, à partir des articles rassemblés et des lieux d'où les auteurs écrivent, on remarquera que le dossier réunit une variété de lieux, d'objets, de point de vues, de pensées, de langages, permettant d'observer, dans sa diversité de genres et de contextes géographiques, nationaux et linguistiques, l'éventail des études possibles et actuellement conduites sur les transferts culturels.

Dirceu Magri - UFV, Brésil

Michel Espagne - ENS-CNRS, France

Éditeurs de ce numéro 